\title{
Baker's Star Tulip, Mariposa Lily
}

Calochortus apiculatus Baker

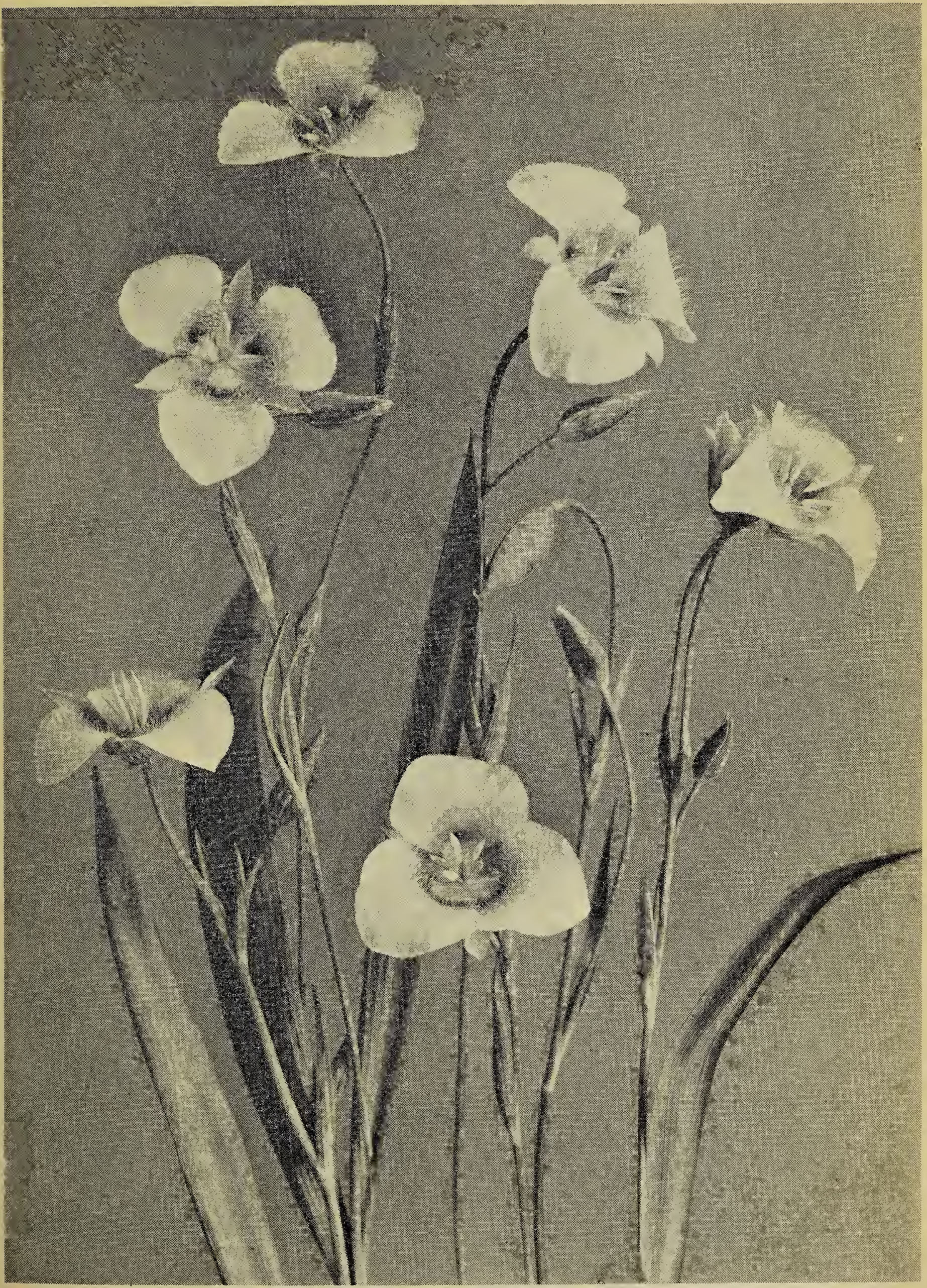

Photo by W. C. MoCalla.

This is one of a group of beautiful plants whose species are most abundant on the Pacific Coast. Dr. Abrams in his Illustrated Flora of the Pacific States describes 41 species and 8 varieties. Of these, two or three are fcund in British Columbia and only this one in Alberta where it seems to be confined to the Waterton Park area, growing on grassy slcpes and in open wocds. Stems are 8 to 16 inches high bearing one to six flowers, sepals pale green, petals creamy yellow with erect yellow hairs on the inner surface Shown here $70 \%$ natural size. 